\title{
CNR: Stability and Growth
}

\section{László Solymosi'}

Published online: 3 August 2018

(c) Springer-Verlag GmbH Germany, part of Springer Nature 2018

Fig. 1 Impact factor development of Clinical Neuroradiology. (Data from: InCites ${ }^{\mathrm{TM}}$ Journal Citation Reports ${ }^{\circledR}$, Clarivate Analytics (www.incites. thomsonreuters.com))

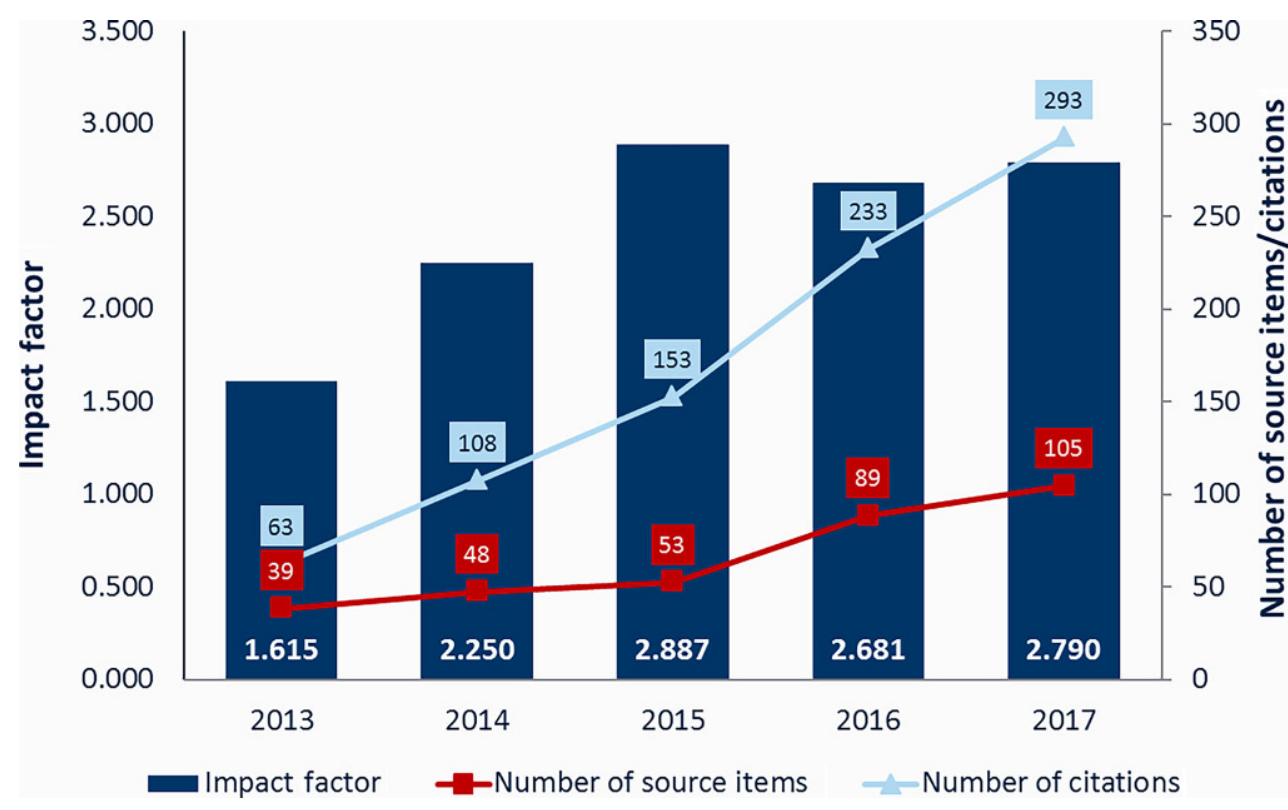

roradiology (CNR) improved slightly compared to 2016 (Fig. 1).

Papers published in CNR are mainly cited in high-ranking journals, e.g. PLoS ONE (IF 2017: 2.766), Journal of Neurosurgery (4.318), European Radiology (4.027) and American Journal of Neuroradiology (AJNR; 3.653) and also in The New England Journal of Medicine (79.258), Lancet (53.254), Brain (10.840) and Stroke (6.239).

The CNR is ranked second in neuroradiological journals, after AJNR (Fig. 2). In the categories where CNR is listed, the journal was able to maintain its rank: in the category "Clinical Neurology" CNR is placed in the top half of journals (rank 88th among 197 journals), in the category "Radiology, Nuclear Medicine \& Medical Imaging", the journal is placed in the first third (ranked 39th in a total of 128 journals).

We are pleased that the situation of CNR is stabilizing in international comparison. A stable position as an international journal is neither a given fact nor can it be maintained without effort, which became apparent when journals such as the International Journal of Neuroradiology, the Neuro-
László Solymosi

solymosi_1@ukw.de

1 Dept. of Neuroradiology, University Hospital of Würzburg, Würzburg, Germany 


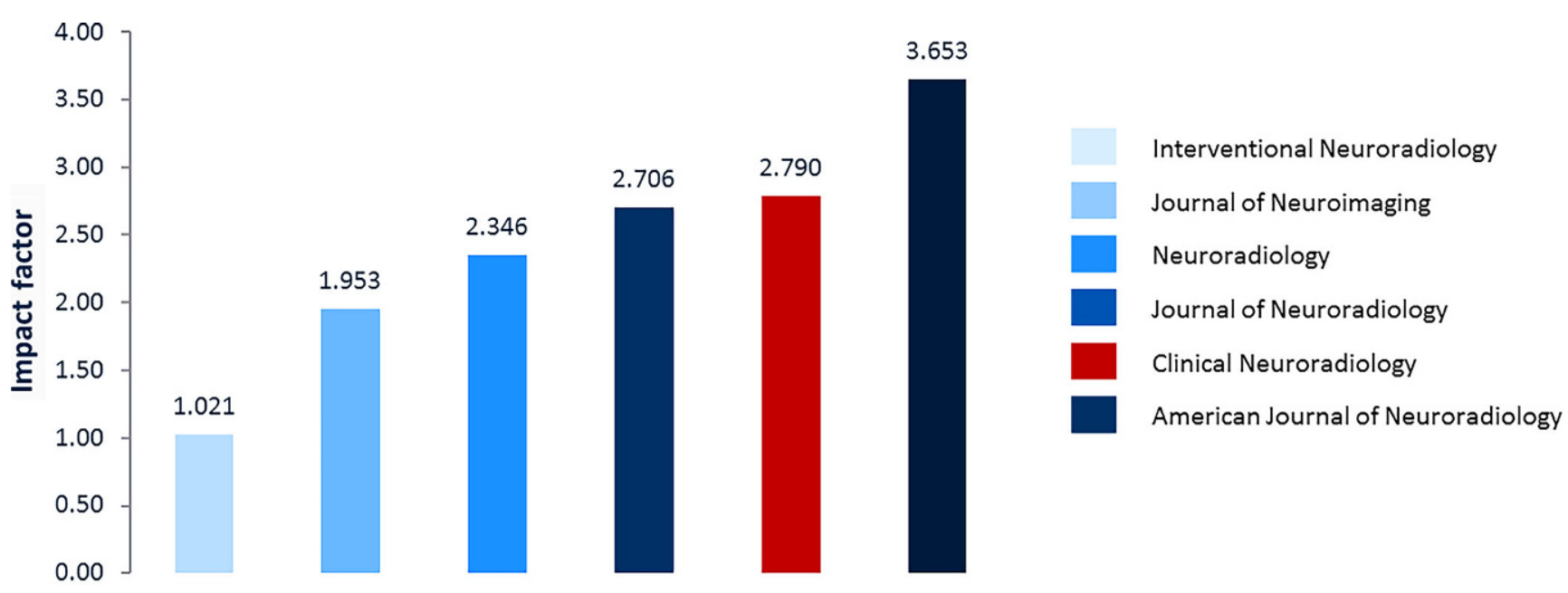

Impact Factor 2017

Fig. 22017 Impact factors of neuroradiology journals in comparison. (Data from: InCites ${ }^{\mathrm{TM}}$ Journal Citation Reports ${ }^{\circledR}$, Clarivate Analytics)

radiology Journal and others did not receive an IF in 2017 anymore.

The number of full-text downloads and submissions continues to increase, so we assume that we are on the right track. We hope that you will continue to support us by submitting good papers, by participating in the peer review process as a reviewer and by diligently citing works published in CNR.
For your support so far, I would like to thank you on behalf of the Editorial Board and Springer Nature

László Solymosi

Editor-in-Chief

Conflict of interest L. Solymosi declares that he has no competing interests. 